\title{
ARUCCIY TUROBRIGA. EL PROCESO DE ROMANIZACIÓN DE LOS LLANOS DE AROCHE
}

\author{
JUAN AURELIO PÉREZ MACIAS \\ NURIA DE LA O VIDAL TERUEL \\ JUAN MANUEL CAMPOS CARRASCO \\ Area de Arqueología. Universidad de Huelva
}

\section{Resumen}

En este trabajo se relacionan las fuentes textuales y arqueológicas de época romana sobre Los Llanos de Aroche, y se propone el modeio de actuación de Roma en sus ciudades de Aruccl y Turobriga. Se concluye que la migración de poblaciones ciudadanas posibilitaria el cambio de estatuto de las antiguas ciudades peregrinas.

\section{Summary}

Roman textual and archeological sources dealing with the Plains of Aroche are studied in this work, and Roman patterns of action in the towns of Aruccl and Turobriga are analyzed. We conclude that the migration of civic populations would facilitate the change of statute of the old pllgrim cittes.

La investigación arqueológica sobre el poblamiento romano en el territorio de la actual provincia de Huelva, ha estado mediatizada tradicionalmente por la gran cantidad de yacimientos mineros en la zona central de la provincia y el continuo hallazgo de espectaculares materiales romanos en ellos. Salvando las notas de Rodrigo Caro (1634) sobre la epigrafía de la zona y la identificación de ciudades, estos descubrimientos, realizados a la par que se reiniciaba la minería onubense a partir del siglo XVIII, siempre despertaron la curiosidad, y en ocasiones el interes cientifico, de ingenieros, geólogos y químicos (Recaredo de Garay, Rúa Figueroa, Tomás Sanz, etc), y dieron ocasión a las 
primeras publicaciones arqueológicas, bañadas siempre en el barniz pedagógico que imponía el Siglo de las Luces (SANZ, 1762)

La acumulación de materiales romanos en las oficinas de las compañias mineras (inglesas, francesas y escocesas) y las publicaciones sistemáticas de algunos geólogos e ingenieros sobre la extensión y amplitud del laboreo minero-metalúrgico romano (GONZALO Y TARIN, 1886: PINEDO VARA, 1963; DELIGNY, 1863; PALMER, 1927; SAlKIELD, 1970), ha contribuido a que se priorice la catalogación de las tierras de Huelva como una de las zonas mineras más explotadas de todo el orbe romano (BLANCO y ROTHENBERG, 1981). Y, sin embargo, la provincia de Huelva tiene otros desarrollos geológicos de tanta extensión como la Franja Pirítica, en los que el estado romano favoreció otras formas de explotación que pudieron complementar a escala regional las demandas de las poblaciones mineras, e incluso, aunque no lo conocemos con seguridad debido a la falta de investigaciones, competir a nivel productivo con la economia de las minas (GONZÁlEZ y PÉREZ, 1986: CAMPOS. TEBA. CASTiNEIRA y BEDIA, 1990). Tales son los casos de la Campiña, la zona agrícola por excelencia, con los centros de gravedad en los oppida de Onoba, Ilipla e Itucci, donde la colonización romana está por estudiar, aunque algunos indicios apuntan a un desarrollo paralelo al del valle del Guadalquivir, del cual es prolongación natural; la Sierra de Aroche, especialmente la comarca de los Llanos de Aroche (vega del Chança), de base agricola y ganadera, donde se encontraban los oppida de Arucci y Turobriga; y la banda costera, salpicada de instalaciones dedicadas a la salazón (CAMPOS, PÉREZ y VIDAL, e.p.)

Este desarrollo y adaptación del modelo romano del oppidum y del municipium en la Tierra Llana de Huelva (Onoba, Ilipla, Ostur e Iptuci). con eje vertebrador en la vía que comunicaba Onoba con Italica (BENDALA GAIÁN, 1987), y en la vega del Chança (Arucci y Turobriga), recorrida por la via de Hispalis a Pax Iulia (ROLDAN HERVÁs, 1975), les concede a estas comarcas una mayor importancia que la zona minera en cuanto a la asimilación de los modelos romanos, pues ésta última estaria salpicada de vici, de los que sólo conocemos los nombres de Urium (LuZÓN NOGUE, 1975; LUZÓN Y RUiz, 1970) y Rubrae (BENDALA GALAN, 1987), que como tertitorios de dominio imperial (agri excepti), estaban sujetos a un régimen juridico especial bajo las directrices de los Procuratores Metallorum.

En este trabajo vamos a centrarnos en el comentario de la romanización en la zona de Aroche, pues la peculiaridad de sus pobladores prerromanos y la política de Roma en este territorium nos permiten ya unas primeras propuestas por las prospecciones y excavaciones que hemos efectuado en la zona (PÉREZ MACIAS, 1987; RODRIGo CÁmARA, 1997; VIDAL y RODRIGO, 1997). Contamos además con un auxiliar de excepción, pues la epigrafia romana de la colección municipal de Aroche es de las más importantes de la provincia de Huelva (GONZALEZ FERNÁNDEZ, 1989).

\section{LA POBLACIÓN PRERROMANA EN LOS PICOS DE AROCHE}

Los Picos de Aroche, o Sierra de Aroche, tal como era conocida en la Baja Edad Media, aparece definida por un valle de origen tectónico que se extiende desde Villa 
Verde de Ficalho (Serpa, Portugai) hasta Valdelarco (Huelva), en el cual se encaja la Rivera de Chança (Guadiana). Este valle, los Llanos de Aroche como se le conoce popularmente, está limitado al Norte por la cadena de Los Picos de Aroche, de dirección herciniana (Este-Oeste), algunas de cuyas alturas alcanzan los 700 metros de altitud (Pico de Ios Ballesteros y la Atalaya) Al sur la cadena de sierras que enmarcan el valle es menos abrupta, aunque tiene más extensión y complejidad. pues aparece dividida por el curso de numerosas riveras que desaguan finalmente al Chança (Alcalaboza, Piernaseca, Raya, etc).

Además de sus grandes posibilidades agrícolas, este valle ha cumplido una función primordial en la comunicación del Bajo Guadiana y el Guadalquivir. Su cuenca hidrográfica está próxima a uno de los afluentes de la margen derecha del Guadalquivir, la Rivera de Huelva, que se inicia precisamente en los alrededores de Valdelarco, donde se encuentra el punto de unión de ambas cuencas fluviales. Este pasillo que siguen ambas corrientes pone en comunicación la zona sevillana, donde desagua la Rivera de Huelva a la altura de Camas, y el Alentejo y Ribatejo portugués. Actualmente es la línea que perfila la carretera Sevilla-Lisboa.

Estas condiciones topográficas contribuyeron sin duda al continuo asentamiento de poblaciones desde la prehistoria, definiéndose un tipo de poblamiento muy influido por el área alentejana y en contacto permanente con el Bajo Guadalquivir. Así se han explicado las peculiaridades de los sepulcros dolménicos de la zona (Grupo de Aroche), alejados de los modelos de la Zarcita y Pozuelo (PIÑON VARELA, 1987), y la existencia de las decoraciones de "reticula bruñida" de tipo portugués, al exterior de los vasos, durante el Bronce Final (PÉREZ MACIAS, 1985).

Las prospecciones extensivas realizadas en la zona también han permitido pergenar la ocupación y el modelo de poblamiento en la II Edad del Hierro (PÉREZ MÁf́as. 1987), el territorio y los habitantes que encontró Roma al ocuparla.

Las poblaciones y sus patrones de asentamiento son radicalmente distintos a los desarrollados durante la Prehistoria Reciente. En ésta última los poblados se situaban en alturas dominantes de las sierras que bordean la Rivera de Chança, y no hemos documentado hasta ahora ningún asentamiento en llano. Esta situación en altura permitía un amplio campo de visibilidad y refugio en momentos de peligro en las zonas más abruptas y recónditas de la sierra, hechos a los que debe obedecer la carencia de líneas de defensa.

Durante la II Edad del Hierro los asentamientos aparecen todos en el Llano y provistos de complicadas líneas de muralla. Son similares a los conocidos en la zona extremeña (BERROCAL RANGEL, 1995) y se corresponden con la definición más usual de los castros. El poblamiento se estructura pues en pequeños poblados fortificados en alturas próximas a las riberas (Chança y Alcalaboza), y ninguno de ellos parece haber desempeñado en momentos antiguos un papel preponderante sobre los demás. Su regularidad a intervalos a lo largo del curso del Chança permite sospechar la delimitación de sus territorios y algún tipo de agrupación política o tribal que los uniera. 


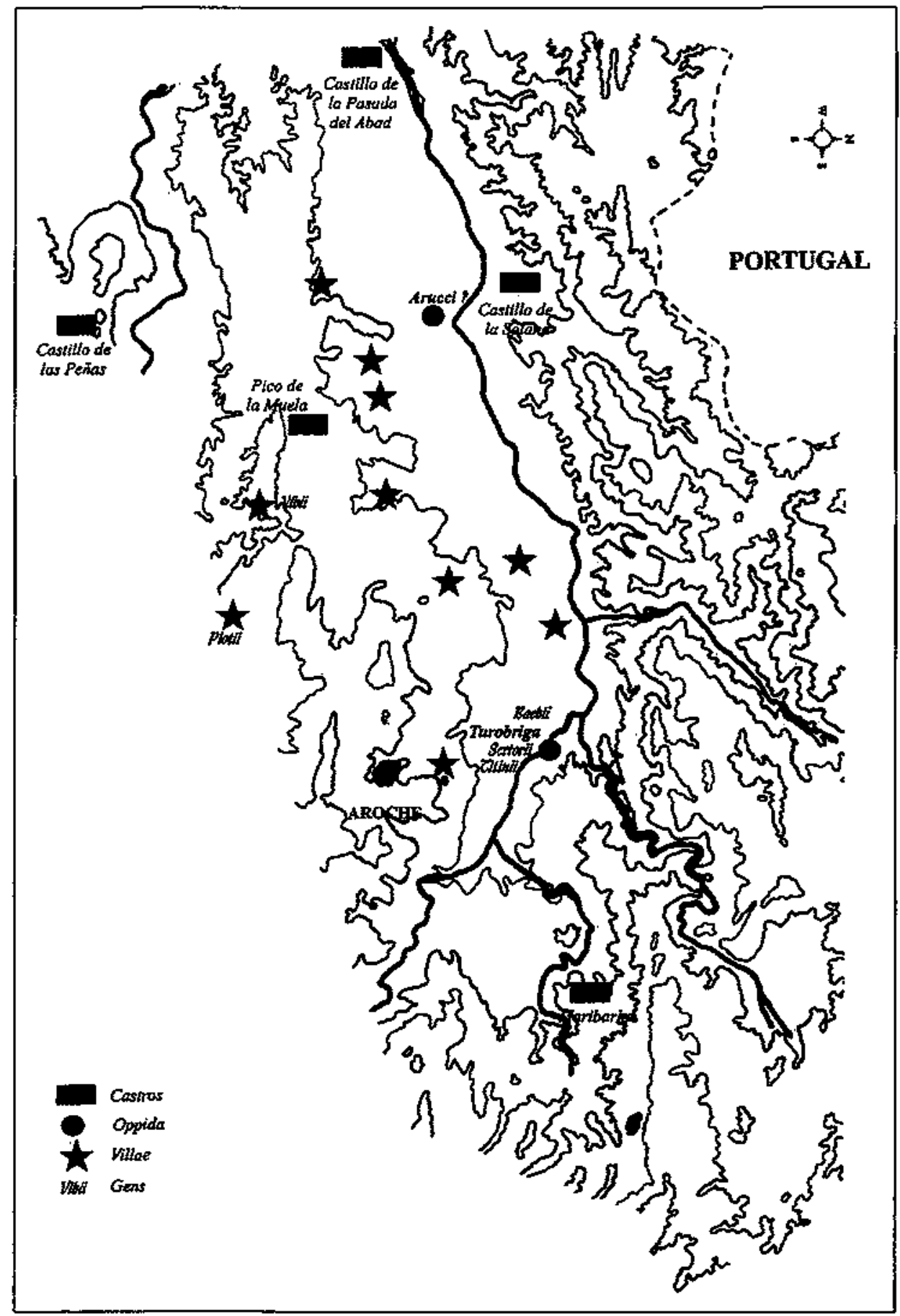

Figura 1.-Poblamiento Prerromano y Romano de la Vega del Chança 
La cultura material de todos estos poblados es netamente diferente a las de las poblaciones costeras turdetanas de las zonas de Huelva y el Bajo Guadalquivir, y encuentran sus paralelos más cercanos en los poblados de Celtici del Suroeste Peninsular (BERROCAL RANGEL, 1985; RODRIGUEZ DIAZ, 1995).

Entre estos poblados pueden citarse el Cerro del Castillo de las Peñas, el Castillo de la Pasada del Abad, la Solana del Torrejón, Pico de la Muela, y Castillo de Maribarba. La evolución del poblamiento es distinta en todos ellos y merece ser descrita siquiera brevemente.

El poblado prerromano del Cerro del Castillo de las Peñas de Aroche es quizás el más importante de todos ellos, tanto por la perduración de la ocupación, como por los elementos conservados (PÉREZ MACIAS, 1987) Este lugar presenta ya signos de habitación durante la Edad del Cobre, especialmente en las laderas del Cerro del Castillo y en los covachos que se abren en ella. Las Peñas de Aroche son un enorme batolito que emerge singularmente en un paisaje dominado por la pizarra con algunas intercalaciones de lentejones calizos. El afloramiento está compuesto por tres alturas, el Marco, el Cerro del Castillo, y los Puntales. El Cerro del Castillo es, de los tres, el que mejores condiciones de habitabilidad proporcionaba, pues su zona superior es amesetada. A esta primera ocupación de la Edad del Cobre corresponden los dólmenes de Los Praditos y Los Puntales, en las zonas llanas a los pies del Cerro del Castillo (PIÑón VARELA, 1987), inaugurándose desde este momento como el área funeraria de las distintas ocupaciones del yacimiento. A partir de un hiatus en la Edad del Bronce, el lugar volvió a ser ocupado durante el Bronce Final y siguió corno área cementerial la zona de Los Praditos, de donde procede un puñal de lengüeta con tipología de este momento (PÉREZ MACfAS, 1985)

El poblamiento hubo de continuar en la II Edad del Hierro, pues tanto de la zona de hábitat como de la necrópolis de los Praditos proceden algunos fragmentos de cerámicas grises estampilladas, características de este momento. Un ajuar de una tumba de incineración prerromana estaba compuesto por una pequena urna gris a torno y dos pequeños vasos de ofrendas a mano. El elemento más singular es, sin embargo, un campo de piedras hincadas (chevaux de frise), similar a los de la Meseta (HARBISON, 1968), que impedía el acceso desde el sur a la cabaliería (PÉrez MACíAS, 1987).

La continuidad del hábitat y el enterramiento en época republicana e inicios de época imperial está confirmada por una lucerna de bronce que procede de la necrópolis de los Praditos, que se encuentra depositada en la Colección Arqueológica Municipal de Aroche, y por fragmentos de cerámica Campaniense B y Terra Sigillata Sudgálica de la zona de hábitat (PÉREZ MAClAS, 1987).

En definitiva, el Cerro del Castillo y la necrópolis de Los Praditos hacen patente una ocupación ininterrumpida hasta los inicios de época julio-claudia. La abundancia de glandes de plomo aparecidos en este yacimiento y conservados en la Colección Arqueológlca Municipal de Aroche debe de estar en relación a las vicisitudes de la ocupacion romana.

El Cerro del Castillo de la Pasada del Abad, situado en el tramo final de los Llanos de Aroche, donde se estrecha la vega formando un embudo, tiene unas constantes de 
poblamiento diferentes. Cumple las características del poblado en llano y tiene muralla que forma dos circuitos, una pequeña ciudadela superior y otra que lo rodea por completo. Los materiales procedentes de este asentamiento no soprepasan los inicios del siglo III a.C. y su momento inicial cabe situarlo en pleno siglo IV a.C. Predominan las cerămicas a mano con ricas decoraciones impresas, digitadas directamente sobre las paredes del vaso, incisas y excisas, y las cerámicas a torno de atmósfera oxidante con decoraciones estampilladas (PÉREZ MACÍAS, 1993a). Es pues un yacimiento interesante desde el punto de vista en que marca el comienzo del asentamiento de Celtici en la vega del Chança, y su abandono o destrucción en los inicios del siglo ili a.C. quizás pueda relacionarse con la extensión de los lusitanos hacia la Baeturia Celtica.

El Castro de la Solana del Torrejón repite un esquema similar de fortificación al de la Pasada del Abad. Se asentó sobre los restos de un asentamiento caicolitico y presenta algunas novedades en sus materiales cerámicos, pues junto a las cerámicas a mano groseras existe la especie gris a torno con decoración estampillada, y algunos galbos de ánforas romano-republicanas del tipo Dressel 1 con el característico desgrasante de origen volcánico y el engobe de tonalidad blanquecina. Algunas monedas de este yacimiento indicarian asímismo una prolongación del hábitat hasta los inicios de la época imperial.

Otro yacimiento con ocupación prerromana es el Cerro del Pico de la Muela (PÉREZ MACfAS, 1994), más alejado de la zona de los Llanos de Aroche, aunque directamente en relación con ellos. Es un hábitat que no parece estar fortificado porque su situación en altura le permite una fácil defensa. Sus cerámicas repiten el esquema tipológico que estamos describiendo, abundancia de cerámicas a mano, algunas decoradas con impresiones e incisiones, y otras pintadas a bandas de color rojo vinoso de tipo turdetano, tónica corriente en otros poblados célticos del suroeste debido a la influencia de las poblaciones costeras. Como en el caso anterior, es significativa la presencia de algunos galbos de ánforas romano-republicanas, síntoma de la permanencia de la población en época romana.

Con menos datos contamos sobre el asentamiento del Castillo de Maribarba, que a juzgar por los materiales calcolíticos de superficie, se estableció sobre un hábitat anterior del III milenio a.C. Los materiales cerámicos son todos a mano, algunos con las típicas decoraciones impresas de este periodo, y no existen materiales encuadrables en época romana (PÉREZ MACfAS, 1987).

Una aproximación a los materiales de superficie de estos poblados nos define un segundo rasgo del patrón de asentamiento. Si en el siglo IV a.C. el nivel de poblamiento estaba caracterizado por pequeños poblados amurallados en las inmediaciones de los Llanos de Aroche (vega del Chança) y en algunos tributarios (Castillo de las Peñas, Castillo de la Pasada del Abad, Solana del Torrejón, Pico de la Muela, y Castillo de Maribarba), en época romano-republicana asistimos a una nítida concentración de la población. especialmente en el Castillo de las Peñas, con abundante material romano, y en la Solana del Torrejón, también con algunos materiales romanos. Según esta misma valoración, el abandono de estos poblados prerromanos debió producirse a comienzos del siglo I d.C.

Los dos poblados que perduraron en época republicana (Castilio de las Peñas y Solana del Torrejón) deben sopesarse en relación a la aparición de los núcleos urbanos 
testimoniados por las fuentes greco-latinas de época imperial. Antes conviene que nos centremos en aclarar su situación y sus peculiaridades.

\section{ARUCCIY TUROBRIGA EN LAS FUENTES}

Tres son los enclaves urbanos citadios en las fuentes greco-latinas que se han situado en la zona de la Rivera de Chança, Arucci, Turobriga y Corticata.

Arucci aparece mencionada entre las ciudades de la Baeturia Celtica en la Naturalis Historia de C. Plinius ("...praeter haec in Celtica Acinipo, Arunda, Arucci, Turobriga, Lastigi, Salpesa, Saepone, Serippo..") en la Geographia de C. Ptolomeus, y como una mansio entre Esuri y Pax Iulia (GONZALEZ FERNANDEZ, 1989). Tradicionalmene se ha identificado con Aroche dada la correspondencia fonetica (CARO, 1634; TOVAR, 1974; LUZON, 1975). Sin embargo, en el casco urbano de la actual población no ha aparecido hasta ahora ningún tipo de material romano o prerromano (CORZO y JIMÊNEZ, 1980; PÉREZ MACfAS, 1987), y las noticias que fueron reseñadas por algunos historiadores locales sobre el emplazamiento de un anfiteatro en el solar del Castillo (DíAZ ALCAIDE, 1966) no pasan de ser conjeturas sin ningún fundamento arqueológico (CORZO y JIMÊNEZ, 1980).

Una inscripción de Aroche, depositada en el Museo de la Biblioteca Municipal de Moura (Portugal) y sus diferentes lecturas han contribuido a que se señalase la existencia de una ciudad homónima en esta localidad portuguesa, cuyo germen se establecía en la propia Arucci, llamada por ello Arucci Vetus (DIAZ ALCAiDE, 1966) frente a la Nova Civitas Aruccitana lusitana (GONZALEZ FERNÁNDEZ, 1989). La inscripción honorífica dedicada a Iulia Agrippina por la Civitas Aruccitana se encontró en la Sierra de Aroche y fue llevada a Moura en el siglo XVI por los Jerónimos, y asi lo confirman Morales (GONZÁleZ y PÉREZ, 1986) y los registros de la Biblioteca del Museo de Moura (ENCARNAÇAO, 1984). La dualidad de dos ciudades se planteó cuando se transcribió el párrafo $N$. CIVITAS ARUCCITANA por Nova Civitas Aruccitana, a pesar de las lecturas de Hübner y Mommsen como IULIAE AGRIPINAE AUG (ustae) $N$ (ostrae) CIVITAS ARUCCITANA (GONZÁlEZ FERNÁNDEZ, 1989). La lectura de Nova Civitas Aruccitana realizada en el siglo XVI por Resende, contestada y desechada por Hübner y Mommsen, fue retomada por Fragoso de Lima (1951) en su afán de identificar a Moura con alguna ciudad romana, distinguiendo un Arucci Vetus (Aroche) y una Nova Civitas Aruccitana (Moura). Esta teoria se mantuvo en las publicaciones posteriores (GARCIA IGLESIAS, 1971; TOVAR, 1974; ROLDAN, 1975), hasta que Encarnaçao (1984) y González Fernández (1989) han desmenuzado la historia de esta inscripción y desvelado la falsedad de una Nova Civitas Aruccitana, Actualmente la polémica se centra en la interpretación de la $N$. transcrita por González Fernández (1989) como $N$ (epti) y por $N$ (ostrae) por Canto (1995), tal como sugerian Hübner y Mormmsen. Nosotros nos decantamos por esta última opinión, que colocaría la inscripción en época de Claudio, pues los datos arqueológicos disponibles de Arucci/Turobriga así lo avalan. 
Resuelto el problema de las dos Arucci en favor de una sola ciudad localizada en la zona de Aroche, los últimos intentos se han centrado en su correcta ubicación. Ya Corzo y Jiménez (1980) señalaron con acierto la imposibilidad de situar la ciudad de Arucci en el casco urbano de Aroche tal como pretendía Luzón Nogué (1975), donde según el desfonde de los solares el poblamiento arrancaría de época almoravide (PÉREZ MACIAS, 1987). y proponian que tal núcleo deberia corresponder a algunos de los numerosos yacimientos romanos de la zona de la Vega del Chança. También se ha propuesto que dado el topónimo prerromano que indica el nombre de la ciudad y en relación al poblamínto prerromano y romano de la zona, Arucci podría localizarse e identificarse con el asentamiento de Fuente Seca (GONZAíEZ y PÉREZ, 1986). Este planteamiento parte del hecho de que en toda la zona en época romana no existen más asentamientos con entidad urbana y monumental que Fuente Seca y San Mamés. y si identificamos San Mamés con Turobriga, tal como más adelante defenderemos, no cabe otra posibilidad que situar Arucci en Fuente Seca. A esta linea de opinión nos conduce también la relación entre el poblamiento romano y el prerromano, que será el argumento de este trabajo.

En otro orden de cosas, la epigrafia aruccitana nos ayuda a conocer otros aspectos importantes de los oppida y del territorium de los mismos. En primer lugar, la mención de Arucci como civitas en el epígrafe dedicado a Iulia Agrippina, segunda mujer de Claudio y madre de Nerón, ha hecho pensar que Aruccl fue Civitas Stipendiaria hasta la generalización del proceso de municipalización de Hispania en tiempos de Vespasiano (GONZÁLEZ FERNÁNDEZ, 1989).

Al contrario de lo que ocurre con Arucci, Turobriga sólo se menciona en la Historia Natural de Plinio como oppidum de la Baeturia Celtica, conventus hispalensis, inmediatamente despuess de Arucci. Fue Albertini (1923) el primero en advertir la ruptura del orden alfabético en la relación de Plinio, y creyó por ello que Arucci y Turobriga podrían constituir una misma unidad toponímica. Leite de Vasconcelos (1871) situó en ella la irradiación del culto a la diosa Ataecina, mientras otros autores que siguieron las localizaciones y situaciones de las inscripciones dedicadas a la diosa Ataecina Turobrigensis, propusieron otros emplazamientos para esta Turobriga donde debería encontrarse el templo de Ataecina; entre ellos Tovar (1974) la situa en los alrededores de Mérida, y Leite de Vasconcelos, como ya hemos señalado, en Arucci. Para Corzo y Jiménez (1980) existirían una Turobriga lusitana, donde debería encontrarse el santuario a Ataecina y desde el que irradió su culto, y una Turobriga beturia localizada en los alrededores de Aroche, que estaría confirmada por la cita de Plinio y la inscripción de Baebia Crinita Turobrigensis. J. M. Luzon habia propuesto antes que el oppidum de Turobriga se podia reducir a los restos romanos de San Mamés (Aroche), donde se distinguía un posible templo que quizás pudiera relacionarse con el de Ataecina. Otros autores, sin embargo, la han situado en el suroeste de la provincia de Badajoz (FERNÁNDEZ CORRALES, 1988).

La aparición de una fistula plumbea en el yacimiento de San Mamés con la inscripción $M . T . F$, creemos que ha resuelto definitivamente la situación de esta Turobriga de la Baeturia Celtica (PÉREZ MAClAS, 1987: GONZALlEZ y PÉREZ, 1986; GONZÁLEZ FERNÁNDEZ, 1989). aunque sobre su lectura hay diversas opiniones. En un principio interpretamos la 
inscripción como $M$ (unicipium) $T$ (urobrigensis) $F$ (ecit), pero A. Canto (1995) ha propuesto $M$ (unicipium) $T$ (urobrigensis) $F$ (istula). Al igual que Corzo y Jiménez (1980) nos inclinamos a considerar que este asentamiento correspondería efectivamente a la Turobriga pliniana, en estrecha conexión con la ciudad de Arucci, con la que debería confinar territorialmente (CAMPOS, PEREZ, RODRIGO y VIDAL, e.p.), pero sería distinta a otra Turobriga, que cabe localizar en la Lusitania, desde donde se extendería el culto a Ataecina, y donde son frecuentes las inscripciones dedicadas a ella, que faltan por completo en la zona de Aroche. A este respecto, es sugerente la propuesta presentada por A. Canto (1995) sobre la existencia en la Baeturia Celtica de ciudades homónimas de otras celitibéricas (Nertobriga), vettonas (Lacinimurga), y lusitanas (Turobriga). Es un fenómeno, ya comentado por el propio Plinio, que explica por sí sólo la formación de la Baeturia Celtica como comarca donde confluyen diversas poblaciones de la Meseta (celtíberos) a través de la Lusitania (vettones y lusitanos) entre los siglos V y ill a.C. (PEREZ MACIAS, 1993b), cuyo reflejo arqueológico está plenamente constatado (BERROCAL RANGEL, 1992; RODRIGUEZ DIAZ, 1991).

Desde el punto de vista de la romanización de la vega de la Rivera de Chança consideraremos en un mismo apartado a Arucci y Turobriga, pues ambas ciudades deberían repartirse en sus territorios toda la zona, y además porque la abundante epigrafia procedente de Aroche en su mayor parte no puede distinguirse como aruccitana o turobrigensis, entre ellas las inscripciones de Baebia Crinita Turobrigensis y la de la Civitas Aruccitana. Por otra parte, a diferencia de la mayoria de las ciudades de la Baeturia Celtica (GARCIA IGLESIAS, 1971), con cognomen Iulia, estas dos ciudades no fueron dotadas de ningün tipo de privilegio en época tardorrepublicana.

El cognomen Iulia de las ciudades de la Baeturia Celtica de la lista de Plinio, como Nertobriga Concordia Iulia (MELIDA, 1925), Lacinimurga Constantja lulia (CANTO, 1995), Seria Fama Iulia (GARCia IGLESIAS, 1971; CANTO, 1995), Segida Restituta Iulia (GONZALEZ y PLiEGo, 1982), y Contributa Iulia Ugultania (FEAR, 1991), delimitan una comarca que se extiende por el sur de la provincia de Badajoz, norte de la provincla de Huelva y sus conexiones con el Valle del Guadalquivir, en las que intervino directamente la política romana en la segunda mitad del siglo I a.C. Sin embargo, este cognomen plantea problemas de atribución a la política de César después de liquidar su enfrentamiento con el bando pompeyano, o a Octaviano antes de recibir el tífulo de Augustus (27 a.C.). De todas formas. ya que desde el punto de vista epigráfico este problema es irresoluble, debemos valorar este cognomen en relación a la política romana en la zona, independientemente de la mano politica que esté detrás de ella. Normalmente este tipo de cognomen se ha relacionado con la constatada política de César de otorgamiento de ciudadanía (VITTINCHOF,1952), latina o romana, pues en este punto no hay acuerdo unánime, y la promoción de municipios y colonias, fenómeno ampliamente documentado en la Península Ibérica (MARfN DÍAZ, 1998). Sin entrar en la polémica, creemos que el caso de Urso. Colonia Iulia Genitiva Urbanorum (MARIN DIAZ, 1988), puede ser recurrente, un plan político cesariano llevado a efecto por Octaviano con la deductio de contingentes. de la plebe urbana de Roma. 
Marín Díaz (1988) se muestra partidaria de considerar que estas ciudades beturias recibirian algún tipo de privilegio (immunitas?), pero no el estatuto de municipium o el ius Latii. Sin embargo, hemos de sopesar la adscripción de individuos de esta zona a la tribu Galeria, a la que tanto César como Augusto incorporaron los individuos promocionados a la ciudadanía, en los casos en que ésta se señala en las inscripciones funerarias (GONZAiEZ FERNÁNDEZ, 1989).

Dejando de lado este punto, sobre el que volveremos a insistir en los párafos siguientes, sí parece claro que de esta política de privilegios quedaron excluidas Arucci y Turobriga, y otras ciudades de celtici de la Batica (Saepone, Arunda, etc). Habrá que indagar también si esta supuesta política de privilegios fue tal, o si por el contrario estos cognomina de la gens Iulia esconden la intervención romana sobre civitates peregrinae y su territorium con deductiones de ciudadanos a los que de algún modo se quería privilegiar con concesiones de tierras a la manera de una asignación viritana, que no implicaba la fundación de una nueva comunidad autónoma administrativamente (GABBA, 1984), según el esquema de la política popular tardo-republicana de asignaciones individuales (CHOUQUER y FAVORY, 1993) De este modo, no deberiamos ver esta política romana como un privilegio, sino como un castigo, la pérdida de autonomia de estas ciudades peregrinas y el asentamiento de ciudadanos.

Esta política de César y Octaviano en la Baeturia Celtica ofrece una tercera lectura. el importante aspecto económico que desempeñaba ya en estos momentos el laboreo minero-metalúrgico de la Franja Piritifera Ibérica (BLANCO y ROTHENBERG, 1981; CHAVES TRISTAN, 1988; PÉREZ MACfAS, 1996). Estas minas, como sucede en el caso de Riotinto principalmente (PÉREZ MACfAS, 1996) sufrieron un fuerte proceso de transformación en cuanto a técnicas mineras y metalúrgicas en la segunda mitad del siglo III a.C., y este nivel de producción industrial se mantuvo constante a lo largo de toda la fase republicana con la metalurgia argentífera como principal actividad. Por otro lado, la Baeturia Celtica fue a lo largo de la etapa republicana un área excesivamente vinculada a la $\mathrm{Lu}$ sitania, cuyas poblaciones probablemente acompañaron y participaron en las endémicas razzias que este pueblo realizaba periódicamente en el Valle del Guadalquivir, hasta tal punto que en algunas ocasiones se nombran algunas ciudades beturias como simplemente lusitanas. Asi se infiere del episodio narrado por Polibio en el que el proconsul de la Hispania Ulterior, Marcus Marcellus, hubo de ser auxiliado por Marcus Atilius, el pretor de la Hispania Citerior, en la toma de la ciudad de Nertobriga en el año 152 a.C.. momento en el que estaba en poder de los lusitanos (SCHULTEN y MALUQUER, 1937), o el posterior de las operaciones de Viriato del año 143 a.C., cuando tomo la ciudad de Iptuci y atacó al pretor Quinctius, que se vió obligado a refugiase en Corduba hasta que la ofensiva de Fabius Maximus Servilianus en el año 141 a.C. le obligó a abandonar Iptuci y refugiarse en la Lusitania, a donde intentaria seguirlo Serviliano después de ocupar algunas ciudades de la Baeturia Celtica (SCHULTEN y MALUQUER, 1987).

La posición de la Baeturia Celtica era de vital importancia para asegurar la tranquitidad tanto del valle del Guadalquivir como de la zona minera de la provincia de Huelva, algunas de cuyas minas estaban a pleno rendimiento en manos de societates pu- 
Bilicanorum (CHAVES TRISTÁN, 1988). El interés por el control de esta zona se deja ver tämbién durante el periodo de la rebelión de Q. Sertorius, como nos lo indican los glandes de plomo de San Sixto (Encinasola), cuando fue ocupada por su lugarteniente Hirtuleyo frente a los ejércitos de $Q$. Cecilius Metellus y $M$. Domicius Calvinus, estrategia que se ha relacionado con el interés de ambos bandos por controlar la zona minera del suroeste (CHIC GARCIA, 1986; DOMERGUE, 1970).

El constante peligro lusitano a causa del prolongado problema social por falta de tierras, hizo considerar a Garcia Bellido (1959) que las promociones y deductiones romanas en la Lusitania tenian un carácter militar, y algunas promociones cesarianas así lo indican (Praesidium Iulium, Norba Caesariana, Olisipo Felicitas Iulia, etc), en un momento en el que se actúa en la Baeturia Celtica y en la zona minera, donde a partir del año 30 a.C. se reforma el sistema de administración (BLAZZUEZ MARTINEZ, 1990), se crean nuevos núcleos de población (PÉREZ MACiAS, 1996), se diversifica la producción (BLANCO y ROTHENBERG, 1981), y se dota a la zona de un sistema de defensa por medio de castella y praesidia (MAIA, 1978)

Hasta este momento los dos núcleos de origen prerromano que citabamos al inicio de este trabajo, el Cerro del Castillo de las Peñas de Aroche y El Castillo del la Solana del Torrejón, a los que llegaban ya algunos productos romanos (campanienses y ánforas Dressel 1), serian civitates peregrinae stipendiariae, que habian sufrido de cerca la presencia de los ejércitos romanos a juzgar por la abundante aparición de glandes de piomo. En estos dos oppida hemos de ver el antecedente de los oppida de Arucci y Turobriga.

Los privilegios concedidos por César o Augusto a algunas ciudades de la Baeturia Celtica no se extendieron a toda la comarca, entre ellas Arucci y Turobriga. Pero los pormenores de la política de Augusto sobre todo pueden rastrearse en estas dos ciudades. A fines del siglo I a.C. los núcleos de origen prerromano del Castilio de las Peñas y Solana del Torrejón seguirían su vida como estipendiarios, a la vez que se constata el asentamiento de ciudadanos romanos en las tierras agrícolas del valle y del distrito minero de La Contienda (CARBONELL, 1922; PÉREZ MACfAS, 1996), cuyos epígrafes funerarios. con fórmulas características de fines de la república, reseñan su inclusión en la tribu $\mathrm{Ga}$ leria (GONZÁLEZ FERNANDEZ, 1989),

Sobre estos pormenores la epigrafia de la zona nos ofrece interesantes indicaciones. Entre las villae rusticae que han aportado epigrafes funerarios se pueden citar la de Santa Clara, de la gens de los Vibii, una de las de texto más amplio y de mayor lujo (BELTRAN FORTES, 1986 y 1994), Carretero, Semedero, Las Españeras, y La Alcalaboza, de la familia de los Plotii (Publius Plotius Reburrus). Como habitantes de la propia Turobriga se pueden citar los Baebii, emparentados por parte materna con los Vibii de Santa Clara (Quinto Vibio Baebiano), y Sertorii.

La inscripción de La Alcalaboza es de las más interesantes, pues nos indica la filiación a la tribu Galeria, propia de las promociones a la ciudadanía en época de César y Augusto, y su lugar de procedencia, la civitas interamniensis (provincia de Orense), con los tria nomina característicos de su ciudadanía. La promoción ciudadana de este indi- 
viduo y su migración hacia la zona de Aroche, donde se asentó como incola, sitúa esta colonización del ager aruccitanus/turobrigensis en tomo al cambio de Era.

Sobre la instalación de los Baebii, o clientes suyos, nos da la pauta una inscripción funeraria de otro miembro de la gens de origo LAC (imurgensis) procedente del yacimiento de San Sixto (Encinasola), adscrito también a la tribu Galeria, y que por la fórmula del epígrafe, la ausencia de dedicación a los dioses Manes (D.M.S.) y el tipo de letra, se puede fechar a caballo entre fines del siglo $\mathbf{I}$ a.C. y los inicios del siglo I d.C. (GONZÁLEZ FERNÁNDEZ,1989). La fórmula de la inscripción de Marcus Sertorius Maternus de La Alcalaboza, con ausencia de D.M.S., corroboraría también el asentamiento de los Sertorii a fines de la República o comienzos del Principado.

Estamos pues ante una importante migración de ciudadanos a comienzos del siglo I d.C., en la que no descartamos la asignación de las fértiles tierras de los Llanos de Aroche (Santa Clara, San Mamés, Carretero, La Zafra, La Zia, Semedero, Españeras, Peñarajada, etc).

Junto a estas poblaciones ciudadanas aparecen también peregrini, como el Secumarus de la inscripción de las Españeras. En relación a la presencia de poblaciones de cives y peregrini aún cabe realizar otra refiexión. Las villae donde se han documentado individuos con tria nomina se encuentran en los alrededores de San Mamés (Turobriga), cuyo límites con el asentamiento de Fuente Seca (Arucci ?) puede quedar delimitado a la altura de la finca Semedero, todavía dentro de los límites de Turobriga a juzgar por la inscripción de un turobrigensis (GONZÁLEZ FERNÁNDEZ, 1989). Este mismo límite aporta el análisis espacial con poligonos Thiessen (HODDER y ORTON, 1990), en el centro de los 13 kilómetros que separan San Mamés de Fuente Seca. Parece sintómatico que en el probable territorium de Fuente Seca sólo haya aparecido una inscripción y es de un peregrino llamado Secumaro.

Creemos que es importante señalar por ello que se produjo un asentamiento de ciudadanos en el territorio de Turobriga, mientras que en la ciudad romana de Fuente Seca existe un fuerte componente indigena, y si es Arucci como sospechamos, daria validez a la expresión civitas Aruccitana como población de peregrini.

La prospección arqueológica de los Picos de Aroche nos permite también otras lecturas de su territorio. pues además de un posible ager asignatus en la zona de la vega del Chança en los alrededores de San Mamés, sus loca agrestia incluían multitud de yacimientos mineros que empiezan a explotarse en esta época (JUBES y CARBONELL, 1920; PEREZ MACLAS, 1996). Estos yacimientos mineros pudieron ser otro de los acicates de la presencia romana en la zona, aunque las posibilidades metalúrgicas de los mismos sea de distinta naturaleza y cualidad que los del Cinturón Ibérico de Piritas, y sus beneficios económicos lógicamente menores. Se trata en general de pequeños filones de sulfuros de cobre de carácter filoniano, y salvo un caso (Mina Frontera) el análisis de la escoria romana ha revelado que sólo se produjo hierro (PEREZ MACIAS, 1996). No obstante, Roma se interesó por la exploración y explotación de estos filones, y en relación a estas labores se podria interpretar la inscripción de un procurator liberto de Nerva encontrada en Aroche (GONZÁLEZ FERNANDEZ, 1989). 
Aunque hoy esos yacimientos mineros se encuentran en su mayor parte en la zona de la Contienda de Aroche y Encinasola, a medio camino entre las civitates de San Mamés (Turobriga) y San Sixto (Lacinimurga ?), el epigrafe dedicado por el liberto imperial como procurator a Nerva, nos indicaría que desde Turobriga se llevaría a cabo la administración de este distrito minero, un fundus exceptus no sometido a la jurisdicción de esta civitas, que englobaría a los distintos vici metallorum, surgidos en torno a los pozos mineros. Tampoco es descartable que algunas familias turobrigenses, como los Vibii o los Baebil, tuvieran intereses como conductores en la explotación de estas minas, pues al menos los Vibil también han sido documentados en el distrito minero onubense de Sotiel Coronada (González Fernández, 1989), una de las minas de la franja pirítica donde la iniciativa privada estuvo más presente (CHAVES TRISTÁN, 1988).

No queremos dejar pasar la ocasión para comentar el problema que envuelve a otra de las supuestas civitates de la Sierra de Huelva, donde se ha situado por el parecido de nombres la Corticata de Claudio Ptolomeo (LUZON NOGUt, 1975). Los restos arqueológicos con los que se identifica, el asentamlento del Campo de Fútbol de Cortegana, distan mucho de ofrecer las características de un núcleo urbano. Por elio, y a pesar de las noticias sobre la procedencia de este lugar de un fragmento de ley municipal (GON. ZALEZ FERNANDEZ, 1988; CANTO, 1986), parece poco probable que el hallazgo se hublera producido en Cortegana. Otras de las posibilidades ofrecidas, la de su procedencia italicense como defiende González Fernandez (1988), tampoco es aceptada de manera unánime por la historiografia debido a que sus concomitancias con la Lex Flavia Municipalis impiden considerar un nuevo cambio de estatuto jurídico de Italica en época flavia, pues ya era municiplo desde época cesariana (MARIN DIAZ, 1988). Podria argumentarse, tal como propone A. Canto (1986), que este fragmento no procediera efectivamente de Cortegana, sino de los alrededores, y en este sentido podría relacionarse con San Mamés (Turobriga) o Fuente Seca (Arucci ?), muy cercanos a Cortegana, que son los únicos asentamientos con entidad urbana de toda la Sierra de Huelva. La datación flavia del fragmento de ley municipal sería un argumento más, pues la opinión generai es que las $c i$ vitates de la Baturia Celtica y la Baeturia Turdula recibieron el estatuto de municipio en este momento (STYLOW, 1991: ÁLVAREZ MARTINEZ, 1993).

\section{ARUCCI Y TUROBRIGA. LOS RESTOS ARQUEOLOGICOS}

Como ya hemos señalado los dos yacimientos de mayor envergadura de toda la vega del Chança son el situado en el paraje de Fuente Seca, también conocido como El Torrejón por un sepulcro turriforme romano que es uno de sus elementos más singulares, y el localizado en los alrededores de San Mamés, de donde proceden algunas inscripciones de turobrigenses y donde se encontró la fistula de plomo que ha permitido identificarlo con Turobriga. 
Las prospecciones superficiales que hemos realizado en el yacimiento de Fuente Seca, no han aportado ningún tipo de material prerromano, y dada su cercana situación al poblado prerromano de La Solana del Torrejon. a apenas trescientos metros de este yacimiento, donde se comprueba la llegada de materiales romanos republicanos (ánforas Dressel 1), es probable que se originara por el traslado de la población a una zona más llana de la vega. Las cerámicas romanas del tipo Terra Sigillata (Sudgálica, Hispánica y Africana) permiten sospechar que tal cambio de ubicación se llevó a cabo a partir del siglo I d.C.

Los restos emergentes más significativos de este yacimiento son un pequeño acueducto de 60 centímetros de anchura por un metro de alto (canalis structilis), con fábrica de opus incertum, y canal (specus) con revestimiento de opus signinum; y un sepulcro turriforme de 3,53 metros de lado, caras orientadas a los puntos cardinales, aparejo de opus incertum y opus testaceum en esquinas, pilares, en el arco de medio punto de una pequeña hornacina, y en rafas para regularizar la obra de mampuestos, cuya parte subterránea está formada por una fosa para el bustum y dos loculi para las ofrendas. Los primeros estudios sobre estos restos identificaron el sepulcro con el caput aquae del acueducto (Luzón Nogué, 1975; Jiménez Martín, 1975) , aunque la posterior excavación de la supuesta fuente determinó que era en realidad un sepulcro turriforme, cuyos ajuares quedaron sin publicar (JMÉNEZ MARTIN, 1975). La revisión realizada de estos elementos considera el acueducto de mediados del siglo I d.C. y el sepulcro turriforme de mediados del siglo II d.C.

Según se desprende de los materiales de superficie, el asentamiento mantendría su poblamiento hasta por los menos el siglo IV d.C., momento en el que se detecta la proliferación de villae rusticae en los alrededores, como La Mazmorra (PÉREZ MACfAS, 1987).

De toda la colección epigráfica de Aroche ninguna inscripción procede con seguridad de este yacimiento. Los epigrafes de fundi cercanos, como las Españeras, corresponden a poblaciones indigenas de peregrini (Secumarus), una coincidencia que no creemos casual, pues por la misma época, segunda mitad del siglo I a.C. y comienzos del siglo I d.C., todos los epigrafes de San Mamés o de turobrigenses son de ciudadanos, con indicación de tria nomina y en algunos con especificación de su inclusión en la tribu Galeria.

Nuestra propuesta de identificar Fuente Seca con Arucci se apoya en el hecho de que no existen en toda la zona de Aroche otros asentamientos de carácter urbano que San Mamés y Fuente Seca. Si reducimos Turobriga a San Mamés, la única posibilidad de situación de Arucci sería Fuente Seca. Aunque puede ser prematuro plantear este tipo de sospecha con tan escasa base, otros razonamientos nos llevan a esta identificación. Turobriga deja de aparecer en las fuentes a partir del siglo II d.C., y no se cita ni en Claudio Ptolomeo ni en el Itinerario de Antonino, en la línea de los materiales aportados por el yacimiento, que indican un paulatino abandono del mismo a partir de época antoniniana, mientras que Arucci se sigue nombrando en esas obras, síntoma de la continuidad del hábitat que está en consonancia con los materiales arqueológicos del yacimiento de 
Fuente Seca. No obstante, también queremos mostrar nuestras reservas hasta disponer de un más profundo conocimiento del yacimiento.

De San Mamés contamos con más elementos de juicio, pues se han realizado tres campañas de excavación, una en su necrópolis y dos en el área monumental. La entidad del yacimiento no pasó inadvertida para J. M. Luzón (1975), quien dada la homogeneidad de las construcciones pensó en un sólo programa edilicio en el que distinguía un posible podium de un templo y un edificio cuadrangular de grandes dimensiones que podía corresponder a una palaestra o una porticus. La peculiaridad de estas construcciones le hizo sospechar que podría tratarse de Turobriga.

La excavación de la zona de su necrópolis en la Huerta de Santa María (LuZÓN No. GUÉ, 1975; ROMÁN y BEDIA, 1987; CUENCA y PAZ, 1997), ha arrojado una cronología encuadrada entre la segunda mitad del siglo I d.C. y la primera mitad del siglo II d.C.

Las dos campañas de excavación llevadas a cabo por el Area de Arqueología de la Universidad de Huelva en la zona urbana, han puesto al descubierto una plaza porticada con pavimento latericio con módulos de $40 \times 20 \times 0,5$ centimetros y monumento central de opus incertum. En el lado sur el muro de cierre es aprovechado en la cimentación de uno de los muros laterales de la Ermita de San Mamés, y el ambulacrum está formado por una doble hilera de pilares (porticus duplex) cuadrangulares de opus incertum. En el lado Oeste, por donde se accedería a la plaza, la hilera de pilares se ve internmpida por una pequeña piscina rectangular revestida de opus signinum. En el lado Norte el ambulacrum cierra con una estructura rectangular de opus incertum no excavada totalmente (taberna? aedes?).

El estado de deterioro del monumento central dificulta su estudio tipológico, aunque algunos fragmentos de escultura de tamaño monumental encontrados en la pequeña piscina, especialmente los fragmentos de una pierna calzada con coturnus venationis, dedos de mano y antebrazo, indicarian que esta estructura estaria destinada a servir de podio a la misma, y la piscina estaría en relación a ella como parte de un juego de aguas.

Los materiales arqueológicos asociados a estas estructuras arrancan de época claudio-neroniana hasta los inicios del siglo III d.C.

Con todos estos elementos se podria identificar este conjunto con un espacio público relacionado con el forum de la ciudad, que incluiría también el podium de opus incertum del templo descrito por J. M. Luzón (1975), que está en correspondencia axial con esta plaza.

Más alejado se encuentra el recinto cuadrangular de opus incertum localizado al norte de la plaza, cuya función a falta de su excavación pensamos que debe relacionarse con un mercado de tipo pecuario.

La preponderancia de los espacios públicos sobre los privados nos ha llevado a plantear que Turobriga cumpliera las funciones de un foro civico y comercial de las poblaciones de los fundos de la zona (CAMPOS, PEREZ, RODRIGO y VIDAL, e.p.).

A pesar del nombre de origen prerromano de Turobriga, las estructuras romanas asientan directamente sobre el suelo natural, y no se han documentado niveles prerro- 
manos, lo que indicaría una fundación realizada ya en época romana en estrecha conexión con las poblaciones ciudadanas emigradas a fines del siglo I a.C. (Baebii, Vibii, Sertorii, Titinit, y Plotit).

\section{CONSIDERACIONES FINALES}

Durante los siglos II y I a.C. la población de los Llanos de Aroche se mantuvo en los asentamientos de origen prerromano de la Solana del Torrejón y Castillo de las Peñas de Aroche. Estas poblaciones, probablemente stipendiariae desde la primera mitad del siglo II a.C., se verían envueltas a mediados de ese siglo en las rebeliones lusitanas contra la política de explotación romana y la venalidad de sus gobernadores, y participarían activamente en la guerra de insumisión sertoriana en la primera mitad del siglo I a.C.

En esta etapa republicana la romanización sería escasa, hasta que en la segunda mitad del siglo I a.C., resueltos los problemas de las guerras civiles en Hispania, las directrices políticas de César y Augusto en la Baeturia Celtica favorecieron un proceso de migración de nuevos ciudadanos, la colonización agricola de la vega del Chança, y la puesta en explotación de los filones minerales de la zona de La Contienda. Este es el momento en el que se documentan los primeros epigrafes funerarios de ciudadanos en las villae rusticae de Aroche (Semedero, Carretero, etc) y en las explotaciones mineras (La Alcalaboza).

Los nuevos asentamientos rurales romanos se produjeron generalmente en el tramo superior de la cabecera del Chança, en los alrededores del asentamiento de San Mamés, donde existían propiedades de miembros o clientes de las familias de Vibii, Sertorii, Baebii, Titinii, y Plotii, algunos de ellos posteriores evergetas de Turobriga (Vibii y Baebil). Estos asentamientos estuvieron dedicados a la producción agrícola, cereales y aceite según se deja ver de los molinos y prensas que, procedentes de estas villae, se encuentran en la colección municipal de Aroche, a la explotación ganadera, y al laboreo minero-metalúrgico.

Esta aceleración del proceso de romanización por la instalación de nuevas poblaciones ciudadanas, se vió favorecida también por la traductio de la población indígena de la Solana del Torrejón y Las Peñas de Aroche hacia nuevas fundaciones romanas, Fuente Seca (Arucci?) y San Mamés (Turobriga), pues el abandono de los asentamientos prerromanos parece coincidir en el tiempo con una contributio de los mismos en los nuevos asentamientos, manteniéndose en este caso los nombres de los oppida prerromanos (Arucci y Turobriga).

Pero a pesar de la intervención directa de Roma sobre el territorio y la población prerromana, esta política no estuvo acompañada con el otorgamiento de los privilegios que se realizó en la mayor parte de la Baeturia Celtica (Nertobriga, Segida, Licinimurga, Seria, etc), y el cambio de condición jurídica de ciudades estipendiarias a municipios no se produciría hasta época flavia, tal como indican el epigrafe de época neroniana de la 
civitas aruccitana y el programa de monumentalización iniciado en Turobriga en momentos flavios.

En definitiva, los escasos datos disponibles permiten establecer la dualidad de poblaciones peregrinas de los asentamientos de origen prerromano y las poblaciones ciudadanas de las villas rústicas, hasta que los traslados de poblaciones y la nueva política de fundaciones, posiblemente en época neroniana a juzgar por los materiales más antiguos de estos asentamientos, doten a la zona de nuevos núcleos urbanos, que cumplirían más unas funciones de mercado regional para favorecer la explotación del territorio (fora), y de centro de la administración de los pozos mineros (procurator).

\section{BIBLIOGRAFIA}

ALBERTINI, E. (1923): Les divisions administratives de l'Espagne. Paris.

Álvarez MARTíneZ, J. M. (1993):" Ciudades romanas de Extremadura". La ciudad hispanorromana. Barcelona.

Beirao, C., Tavares, C.; SoARes, J.. Vareala, M., y Varela, R. (1985):" Depósito vótivo da II Idade do Ferro de Garvao-Noticia da primera campanha de excavaçoes". OArqueologo Portugues, 3 , serie IV Lisboa.

BEITRAN ForTÉS, J. (1986): "De epigrafia Aruccitana". XX Congreso Nacional de Arqueología. Zaragoza.

- (1994): "Consideraciones sobre algunos tipos de soportes epigráficos del Suroeste de la Península Ibérica". Arqueología en el Entorno del Bajo Guadiana. Huelva.

BENDALA GALÁN, M. (1987): "Ab Ostio fluminis Anae Emeritam usque"; Cuadenos de Prehistoria y Arqueologia, 13-14. Madrid.

Berrocal Rangel, L. (1992). "Los pueblos celticos del Suroeste de la Península Ibérica". Complutum extra, 2. Madrid.

- (1995) "La Beturia. Definición y caracterización de un territorio prerromano". Cuadernos Emeritenses, 9. Mérida.

BlANCO, A., y ROTHENBERG, B. (1981): Exploración Arqueometalúrgica de Huelva. Barcelona.

BLAZQueZ MARTINEZ, J. M. ${ }^{2}$ (1990) "Administración de las minas en época romana. Su evolución". Mineria y Metalurgia en las antiguas civilizaciones mediterráneas y europeas, I. Madrid.

CAMPOS, J. M.; TEBA, J. A.; CASTIÑEIRA. J., y BEDiA, J. (1990): " La documentación para el estudio de la romanización en la provincia de Huelva, Huelva en su Historia 3.

CAMPOS, J. M.; PÉREZ, J. A., y VIDAl, N. O. (e.p.): "Las industrias de salazones en la costa onubense". II Encontro de Arqueologia do Sudoeste da Peninsula Iberica. Faro, 1996. 
CAMpoS, J. M.; PEREZ, J. A., RodRIGo, J. M.". y VIDAL, N. O. (e.p.): "Ager y Municipium Aruccitanus" XII Jornadas de Patrimonio de la Sierra de Huelva. Aracena, 1997.

CANTO, A. M. (1991):" Noticias arqueológicas y epigráficas sobre la Beturia Céltica". Cuadernos de Prehistoria y Arqueologia, 18. Madrid.

- (1995)." La Baeturia Celtica. Introducción a su epigrafia" Celtas y Turdulos en la Baeturia. Cuadernos Emeritenses, 9. Mérida.

- (1986): "A propos de la loi municipal de Corticata (Cortegana, Huelva, Espagne)" Zeitschrift für Papyrologie und Epigraphik, 63.

CARBONELL, A. (1922) " Lucerna ibérica de la Contienda de Moura". Boletín de la Real Academia de Córdoba, 2. Córdoba.

CARO. R. (1634): Antigüedades y Principado de la Ilustrissima Ciudad de Sevilla y Chorografia de su convento juridico. Sevilla.

CHAVES TRISTÁN, F. (1988)," Aspectos sobre la circulación monetaria en la provincia de Huelva" II Jornadas de Patrimonio de la Sierra de Huelva. Sevilla.

ChIC Garcfa, G. (1986) "Q. Sertorius Procónsul" Actas Reunión sobre Epigrafía Hispánica de época romano-republicana. Zaragoza.

ChOuQuer, G., y FAvORY, F. (1993):" De arte mensoria, "Du métier d'arpenteur". Arpentage et arpenteurs au service de Rome" Historla et Mesura, VIII-3/4. Paris.

CORZO, R., y JimÉnEZ, A. (1980): "Organización territorial de la Bética". Archivo Español de Arqueologia, 53. Madrid.

DELIGNY, E. (1963) "Apuntes históricos sobre las minas cobrizas de la Sierra de Tharsis (Tharsis, Boetica)", Revista Minera XIV. Madrid.

DIAZ ALCAIDE, P. (1966) Aroche, turístico, histórico y monumental, la antigua Arucci Vetus romana. Sevilla.

DOMERGUE, C. (1970):" Un temoignage sur l' industrie minière et metallurgique du plomb dans la region l' Azuaga (Badajoz) pendant la guerre de Sertorio" XI Congreso Nacional de Aqueología. Zaragoza.

EnCARnAÇAO, J. (1984): Inscriçoes Romanas do Conventus Pacensis. Coimbra.

FEAR, A.T (1991):" Contributa Iulia, Uguitania and Curiga". Gerión, 9. Madrid

FERNANDEZ CORRALES, J. M. (1988). El asentamiento romano en Extremadura y su análisis espacial. Cáceres.

FRAGOSO DE LIMA, J. (1951)." Aspectos da romanizaçao no território portugués da Betica". O Arqueologo Portugues, Nova Serie, 1. Lisboa.

GABBA, E. (1984):" Per un' interpretazione storica della centuriazione romana". Misurare la terra. centurizione e coloni nell mondo romano. Módena.

GARCiA Y BelLIDO, A. (1959):" Del carácter militar activo de las colonias de Lusitania y regiones inmediatas". Trabalhos de Antropologia e Etnografia, 117. Oporto. 
GARCIA IGLESIAS, J. A. (1971):" La Baeturia, un probiema geográfico de la Hispania Antigua" Archivo Español de Arqueologia, 44. Madrid.

GONZALEZ FERNANDEZ, J. (1988):" De nuevo sobre el fragmento italicense de Ley Municipal". II Jornadas de Patrimonio de la Sierra de Huelva. Huelva.

- (1989) Corpus de inscripciones latinas en Andalucia. Huelva. Sevilla.

GONZALEZ, J., y PÉREZ, J.A. (1986) " La Romanización en Hueiva". Huelva y su Provincia, II. Cádiz.

GONZÁLEZ, J., y PLIEGO, F. (1982):" Las monedas con leyenda Ilse y el emplazamiento de Ségida Restituta Iulia". Numisma, 177-179. Madrid.

GONZALO Y TARíN, J. (1886): "Descripción fisica, geológica y minera de la provincia de Huelva" Memorias de la Comisión del Mapa Geológico de España. Madrid.

HARBISON, P. (1968):" Castro with Chevaux-de-frise in Spain and Portugal". Madrider Mittellungen, 9. Mainz.

HODDER, I., y ORTON, C. (1990): Análisis espacial en Arqueología. Barcelona.

JIMÉNEZ MARTIN, A. (1975):" El yacimiento romano de Fuente Seca de Aroche" Noticiario Arqueológico Hispano, 4. Madrid.

JUBES, E., y CARBONELL, A. (1920):" Estudio geológico industrial de los yacimientos minerales del término de Encinasola y la Contienda de Moura". Boletín Oficial de Minas y Metalurgia, 34-39. Madrid.

LEITE DE VASCONCELOS. J. (1913). As religioes da Lusitania. Lisboa.

LUZON NOGuE, J. M. " (1975): "La Romanización". Huelva. Prehistoria y Antigüedad. Madrid.

LUZÓN NoGUE. J M. ${ }^{a}$ y RUIZ MATA, D. (1970): "El poblado minero romano de Riotinto". Habis, 1. Sevilla.

MAIA, M. (1978):" Fortalezas romanas do Sul de Portugal" Zephirus, XXVIII. Salamanca.

MARIN DIAZ, M. A. (1988). Emigración, colonización y municipalización en la Hispanta republicana. Granada.

MéLidA, J. R. (1925) Catálogo monumental de Badajoz. Madrid.

PALMER, R. E. (1927). "Notes on some ancient mining equipments and system", Transaction Institution of Mining and Metallurgy, XXXV. Londres.

PÉREZ MACfAS, J. A. (1985): "Introducción al Bronce Final en el Noroeste de la provincia de Huelva". Habis, 14. Sevilla.

- (1987). Carta Arqueológica de los Picos de Aroche. Huelva.

- (1993a): "Cerámicas prerromanas de la Pasada del Abad (Rosal de la Frontera, Huelva)". Boletín de la Sociedad Española de Amigos de la Arqueología, 33. Madrid.

- (1993b):" Poblados de la Edad del Hierro en la Sierra de Huelva. Orígenes e influencias en la formación de la Baeturia Celtica". Trabalhos de Antropologia e Etnologia, 33 (3/4) Oporto. 
- (1994):" El Puerto de la Muela. Nuevo asentamiento prerromano en la margen izquierda del Guadiana". Norba, 11-12. Cáceres.

- (1996) . La producción de metales en el Cinturón Ibérico de Piritas en la Prehistoria y Antigüedad, Huelva.

Pinedo Vara, I. (1963): Piritas de Huelva. Su historia, mineria y aprovechamiento. Madrid.

PIÑon VARELA, F. (1987): "Los constructores de sepulcros megalíticos". Huelva y su Provincia, II. Cádiz

RESENDE, A. (1790): De antiquitatibus Lusitaniae caeteraque historica, quae extant. Coimbra

Rodrigo CÁmara, J. M. (1997): Informe Ermita de San Mamés (Aroche, Huelva). Intervención Arqueológica de Apoyo a la Restauración. Delegación Provincial de Cultura de Huelva. Junta de Andalucia. Inédito.

RODriguez DiAz, A. (1991). La Ermita de Belén (Zafra, Badajoz). Campaña de 1987. Mérida.

- (1995):" Extremadura prerromana". Extremadura Arqueologica, IV Madrid.

ROLDÁN HERVÁ, J. M.(1975): Itineraria Hispana. Valladolid.

Schulten, A. y Maluquer, J. (1987):" Hispania Antigua según Pomponio Mela, Plinio el viejo y Claudio Ptolomeo". Fontes Hispaniae Antiquae, VII. Barcelona.

SALKIELD. L. V. (1970): "Ancient slag in the south west of the Iberian Peninsula", Mineria Hispana e Iberoamericana. León.

SANZ, T. F. (1762): Memoria Antigua de Romanos nuevamente descublerta en las Minas de Riotinto. Sevilla.

STYLOW, A. U. (1991):" El municipium Flavium V (-) de Azuaga (Badajoz) y la municipalización de la Baeturia Turdulorum". Studia Historica, 9. Salamanca.

TOVAR, A. (1974): Iberische Landeskunde zweiter Teil. Die Volker und die Städte des antiken Hispanien. Bd. 1. Baden-Baden.

VIDAL TERUEL, N. O., y RODRIGo CÁmARA, J. M. ${ }^{a}$ (1997): Informe preliminar de la actuación de emergencia realizada en el yacimiento de San Mamés, Fase II (Aroche. Huelva) Delegación Provincial de Cultura de Huelva. Junta de Andalucía. Inédito.

VITTINGHOFF, F.(1952). Römische Kolonisation und Bürgerrechtspolitik unter Caesar und Augustus. Weisbaden. 